[Agr. Biol. Chem., Vol. 35, No. 5, p. 756 763, 1971]

\title{
Gas Chromatographic and Mass Spectral Analyses of Heated Flavor Compounds of Beef Fats
}

\author{
By Kenji Watanabe and Yasushi Sato \\ Laboratory of Food Science \& Technology (Animal Products), Faculty of Agriculture, \\ Nagoya University, Nagoya, Japan \\ Received October 16, 1970
}

\begin{abstract}
The volatile compounds from beef fats heated under the cooking condition- $145^{\circ} \mathrm{C}$, $10 \mathrm{~min}$-were isolated, and nonacidic compounds separated from them were further fractionated into five fractions by silicic acid column chromatography. The odor of nonacidic compounds significantly resembled the heated flavor of beef fats. Several carbonyl compounds, hydrocarbons, alcohols, lactones and pyrazine compounds in the fractionated compounds were identified with the techniques of gas chromatography and gas chromatography-mass spectrometry. Their possible contribution to the heated beef fat flavor was discussed. The typical heated flavor could probably be ascribed to a proper combination of aldehydes, ketones, esters and sulfur-containing compounds.
\end{abstract}

There is a general agreement among investigators that meat fats as well as the lean portion of the meat are one of the important sources of meat cooked flavors. Several attempts $^{1-4}$, have been made to identify the volatile compounds which were obtained from meat fats by heating or steam-distillation. However, most of the above studies dealt with the carbonyl compounds among the total flavor compounds. It is difficult, therefore, to evaluate all of the flavor compounds from cooked meat fats.

The present investigation was undertaken to identify the various flavor compounds from beef fats heated under the cooking condition, and to confirm the relation between the volatile nonacidic compounds and the flavor.

1) T. Yamato, T. Kurata, H. Kato and $M$. Fujimaki, Agr. Biol. Chem., 34, 88 (1970).

2) I. Hornstein and P. F. Crowe, J. Agr. Food Chem., 11, 147 (1963).

3) A. M. Gaddis, R. Ellis and G. T. Currie, J. Am. Oil Chem. Soc., 38, 371 (1961).

4) A. M. Gaddis, R. Fllis and G. T. Currie, Food Res., 24, 283 (1959).

\section{EXPERIMENTAL}

1. Material. Bovine leaf fats were used as beet fats sample.

2. Heat treatment. The apparatus for the collection of flavor compounds produced by heat is shown in Fig. 1. The heat treatment of beef fats was done under the cooking condition $-145^{\circ} \mathrm{C}, 10 \mathrm{~min}$-deviced from cooking of the Japanese "Sukiyaki." The pan (A), $24 \mathrm{~cm}$ in diameter and $7 \mathrm{~cm}$ in height, made of alumite, was covered by the glass lid $(B)$, which was fitting with the pan. The top of the lid was connected with the condenser (D), the train of traps ( $E$ through $\mathrm{J}$ ) and the flowmeter $(\mathrm{K})$ in order. And then a sucker was connected to the end of the flowmeter. For heating, the pan which was lowered with the aid of laboratory jack (L) was maintained at $145^{\circ} \mathrm{C}$, and as soon as $400 \mathrm{~g}$ of fats was added into the pan, the lid was closely put on its pan without leakage of flavor. The produced flavor compounds and steam were drawn with the current of air through the cold traps at a rate of 1 liter per min, as checked by the flowmeter. After heating for $10 \mathrm{~min}$ at $145^{\circ} \mathrm{C}$, the pan was lowered with the jack and then the heated fats were taken out from the pan. Inside surface of the pan and glass lid were wiped out with papers after every heating. Ten kg of beef fats was treated by the repeats of these opera- 


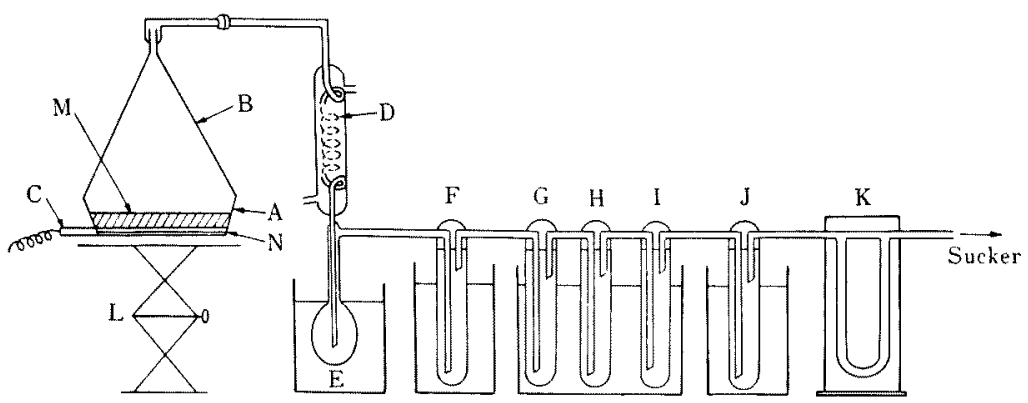

FIG. 1. Apparatus for Heating.

A; pan, B; glass lid, C; temperature regulator, D; condenser, E; trap cooled with water, F; trap cooled with ice, G-I; traps cooled with dry ice in acetone, J; trap cooled with liquid nitrogen, $\mathrm{K}$; flowmeter, L; laboratory jack, $\mathrm{M}$; sample, $\mathrm{N}$; heater.

tions. All of the condensates in the cold traps were extracted with ethyl ether.

3. Separation of nonacidic compounds. The separated ethyl ether solution was washed with $5 \%$ sodium carbonate solution to remove the fatty acids. The washed ethyl ether solution was dried over anhydrous $\mathrm{Na}_{2} \mathrm{SO}_{4}$ and fractionally distilled with $1 \times 30 \mathrm{~cm}$ column packed with glass helices to remove the bulk of the ethyl ether. A part of the concentrated total nonacidic compounds was analyzed by gas chromatography and the combination of gas chromatographymass spectrometry.

4. Fractionation of nonacidic compounds. The most part of total nonacidic compound was fractionated into five fractions by silicic acid column chromatography. The $1.7 \times 13 \mathrm{~cm}$ column was packed with $15 \mathrm{~g}$ of silicic acid (Mallinckrodt, 100 mesh). The column was successively eluted with each $100 \mathrm{ml}$ of pentane, pentane-ethyl ether $(7: 3)$, pentane-ethyl ether $(4: 6)$, ethyl ether and ethyl ether-methanol $(9: 1)$. Each eluted solution was fractionally distilled, and then the concentrates of each fraction were analysed by gas chromatography and gas chromatography-mass spectrometry. All of the solvents used were purified by distillation.

5. Gas chromatography. The gas chromatographic analyses were performed on a Hitachi K-53 Model Gas chromatograph with a flame ionization detector, using a $3 \mathrm{~mm} \times 2 \mathrm{~m}$ column containing $10 \%$ PEG-20M on $80 \sim 100$ mesh Celite 545 . The temperature were programmed from 50 to $220^{\circ} \mathrm{C}$ at a rate of $2^{\circ} \mathrm{C}$ per min.
6. Gas chromatography-mass spectrometry. A combined instrument of gas chromatograph-mass spectrometer, Hitachi RMU-6E Model, was used. The flavor concentrates of each fraction were injected into a $3 \mathrm{~mm} \times 2 \mathrm{~m}$ column packed with 1090 PEG $-20 \mathrm{M}$ on Celite 545, 80 100 mesh. The column temperatures were programmed from 50 to $220^{\circ} \mathrm{C}$ at a rate of $2^{\circ} \mathrm{C}$ per min. Helium carrier gas pressure was 1.0 $\mathrm{kg} / \mathrm{cm}^{2}$. The column effluent was admitted via a heated line to a Watson-Biemann helium separator and then to the ion source. Mass spectrometric conditions were as follows; ion accelerating voltage$1800 \mathrm{~V}$, ionizing voltage- $70 \mathrm{~V}$, total emission $-80 \mu \mathrm{A}$, target emission- $72 \mu \mathrm{A}$, ion source temperature $-220^{\circ} \mathrm{C}$, multiplier $-3 \mathrm{KV}$. Mass spectra were taken at the apices of peak of gas chromatogram.

7. Reference compounds. The reference compounds commercially available were offered by chemical supplies. Pyrazine compounds were synthesized by the method of Praag et al.51

\section{RESULT AND DISGUSSION}

The total nonacidic compounds ( $\mathrm{T}-\mathrm{Fr}$ ) obtained from beef fats were highly flavorful, and their flavor remarkably resembled their original one of the cooked beef fats at proper dilution in air. Fraction I (solvent; pentane), II (pentane-ethyl ether $7: 3$ ), III (pentane-

5) M. van Praag, H.S. Stein and M.S. Tibbetts, J. Agr. Food Chem., 16, 1005 (1968). 

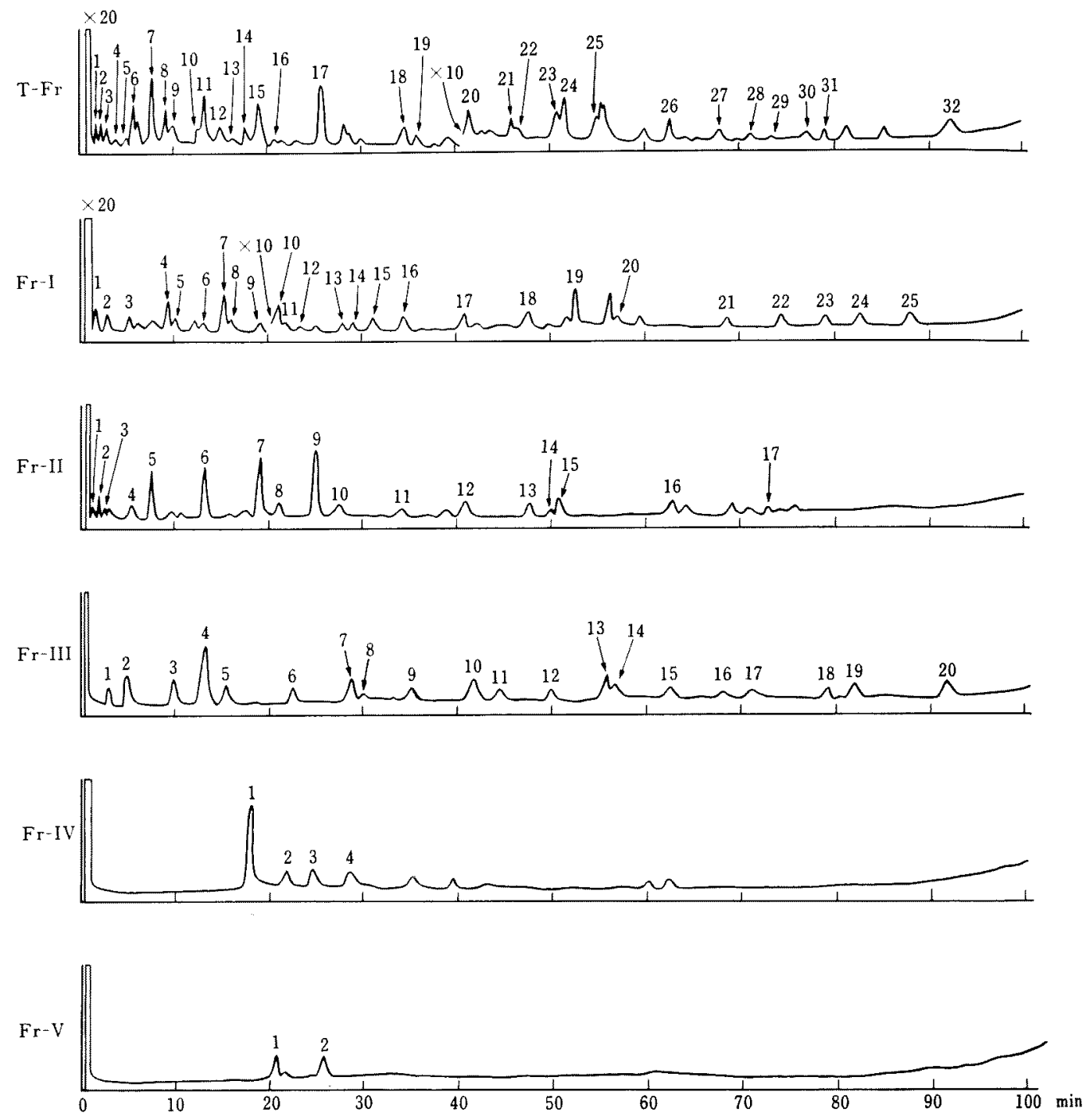

FIG. 2. Gas Chromatograms of T-Fr and Fr I, II, III, IV and V.

Hitachi K-53 Gas Chromatograph, flame ionization detector, 10\% PEG-20M on 80/100 mesh Celite $545(3 \mathrm{~mm} \times 2 \mathrm{~m}), \mathrm{N}_{2} ; 0.2, \mathrm{Air} ; 1.5, \mathrm{H}_{2} ; 0.6 \mathrm{~kg} / \mathrm{cm}^{2}$, Column Temp.; $50 \underset{2^{\circ} \mathrm{C}}{\longrightarrow} 220^{\circ} \mathrm{C}$.

ethyl ether 4:6), IV (ethyl ether) and V Fr II; greenish and tallowish flavor, Fr III; (ethyl ether-methanol 9:1), which were frac- sweetish and mashroom-like flavor, Fr IV; tionated by silicic acid column chromato- potato chips-like flavor, $\mathrm{Fr} \mathrm{V}$; roasted and graphy, had a characteristic flavor in itself, burnt-like flavor. And all of the fractions that is, Fr I; pale and hydrocarbon-like flavor, had, more or less, a characteristic onion and 
Table 1. Nonacidic Compounds Obtained from the Heated Beef fats

\begin{tabular}{|c|c|c|c|c|c|}
\hline Compounds & Fraction and & d peak No. & $\begin{array}{c}\text { Retention } \\
\text { sample }\end{array}$ & $\begin{array}{l}\text { time }(\min ) \\
\text { reference }\end{array}$ & $\begin{array}{c}\text { Mass spectral peak } \\
\mathrm{M}^{+} / m / e\end{array}$ \\
\hline Octane & $\mathrm{T}-1$ & $I-1$ & 1.7 & 1.7 & $114 / 43,57,29$ \\
\hline Ethyl formate & & II-I & 1.9 & 1.9 & $74 / 31,28,29$ \\
\hline Ethyl acetate & $\mathrm{T}-2$ & II -2 & 2.7 & 2.6 & $88 / 43,29,45$ \\
\hline Nonane & & I -2 & 3.0 & 2.9 & $128 / 43,57,29$ \\
\hline Ethanol & $T-3$ & III-1 & 3.3 & 3.3 & $46 / 31,45,46$ \\
\hline Isovaleraldehyde & $\mathrm{T}-3$ & II-3 & 3.4 & 3.4 & $86 / 44,41,43$ \\
\hline Benzene & $\mathrm{T}-4$ & & 3.9 & 4.0 & $78 / 78,43,57$ \\
\hline$n$-Pentanal & $T-5$ & II-4 & 4.6 & 4.5 & $86 / 44,29,58$ \\
\hline 2-Butanol & & III -2 & 5.3 & - & $74 / 45,27,29$ \\
\hline Chloroform & $\mathrm{T}-6$ & & 5.6 & 5.6 & $118 / 83,85,47$ \\
\hline Decane & $\mathrm{T}-6$ & $\mathbf{I}-3$ & 5.6 & 5.6 & $142 / 43,57,41$ \\
\hline$n$-Hexanal & $\mathrm{T}-7$ & II-5 & 8.0 & 8.1 & $100 / 44,56,41$ \\
\hline Undecane & $\mathrm{T}-8$ & $\mathrm{I}-4$ & 9.5 & 9.4 & $156 / 43,57,71$ \\
\hline n-Butanol & & III-3 & 10.2 & 10.1 & $74 / 31,56,41$ \\
\hline$m$-Xylene & $\mathrm{T}-9$ & $\mathrm{I}-5$ & 10.2 & 10.2 & $106 / 91,106,105$ \\
\hline o-Xylene & $\mathrm{T}-10$ & $I-6$ & 13.0 & 13.0 & $106 / 91,106,105$ \\
\hline n-Heptanal & $\mathrm{T}-11$ & II -6 & 13.4 & 13.2 & $114 / 70,55,57$ \\
\hline Isoamylalcohol & $\mathrm{T}-11$ & III -4 & 13.6 & 13.4 & $88 / 41,70,55$ \\
\hline Dodecane & $\mathrm{T}-12$ & I-7 & 14.7 & - & $170 / 57,43,71$ \\
\hline n-Pentanol & $\mathrm{T}-13$ & III-5 & 16.0 & 15.8 & $88 / 42,31,29$ \\
\hline Cumene & & $1-8$ & 16.1 & 16.2 & $120 / 105,120,77$ \\
\hline Acetoin & $T-14$ & IV -1 & 18.0 & 18.3 & $88 / 45,43,88$ \\
\hline Alkylbenzene & & $\mathrm{I}-9$ & 18.2 & - & $134 / 119,91,134$ \\
\hline$n$-Octanal & $\mathrm{T}-15$ & II -7 & 19.0 & 18.8 & $128 / 43,41,44$ \\
\hline Tridecane & $\mathrm{T}-16$ & $\mathrm{I}-10$ & 20.8 & - & $184 / 57,43,71$ \\
\hline 2,5-Dimethyl pyrazine & & $V-1$ & 21.2 & 21.0 & $108 / 108,42,39$ \\
\hline 2-Ethyl pyrazine & & IV -2 & 21.4 & 21.4 & $108 / 107,108,80$ \\
\hline 2-Heptenal & & II -8 & 21.5 & 22.0 & $112 / 43,41,56$ \\
\hline Alkylbenzene & & $1-11$ & 22.0 & - & $148 / 105,91,148$ \\
\hline$n$-Hexanol & & $111-6$ & 23.7 & 23.9 & $102 / 56,43,55$ \\
\hline Alkylbenzene & & $1-12$ & 24.0 & - & $148 / 119,91,148$ \\
\hline 2-Ethyl-5-methyl pyrazine & & IV -3 & 24.9 & 25.0 & $122 / 121,122,39$ \\
\hline$n$-Nonanal & $T-17$ & II-9 & 25.6 & 25.7 & $142 / 57,41,43$ \\
\hline 2,3,5-Trimethyl pyrazine & & $\mathrm{V}-2$ & 26.4 & 26.9 & $122 / 42,122,39$ \\
\hline Tetradecane & & $\mathrm{I}-13$ & 27.7 & - & $198 / 57,43,71$ \\
\hline 2-Octenal & & II -10 & 28.1 & 28.0 & $126 / 41,70,55$ \\
\hline 2-Ethyl-3,6-dimethyl pyrazine & & IV -4 & 28.4 & 28.2 & $136 / 135,136,42$ \\
\hline$n$-Heptanol & & III -7 & 28.7 & 28.4 & $116 / 41,43,56$ \\
\hline 1-Octene-3-ol & & III-8 & 29.0 & - & $128 / 57,43,29$ \\
\hline Alkylbenzene & & $1-14$ & 29.0 & - & $162 / 147,119,91$ \\
\hline Alkylbenzene & & I -15 & 30.5 & - & $162 / 147,133,105$ \\
\hline Pentadecane & $\mathrm{T}-18$ & I -16 & 34.2 & - & $212 / 57,43,71$ \\
\hline 2-Nonenal & & II-11 & 34.3 & 34.5 & $140 / 55,70,57$ \\
\hline$n$-Octanol & $\mathrm{T}-19$ & III-9 & 35.5 & 35.2 & $130 / 56,55,41$ \\
\hline Hexadecane & & $1-7$ & 40.6 & - & $226 / 57,43,71$ \\
\hline
\end{tabular}


TABLE I. (continued)

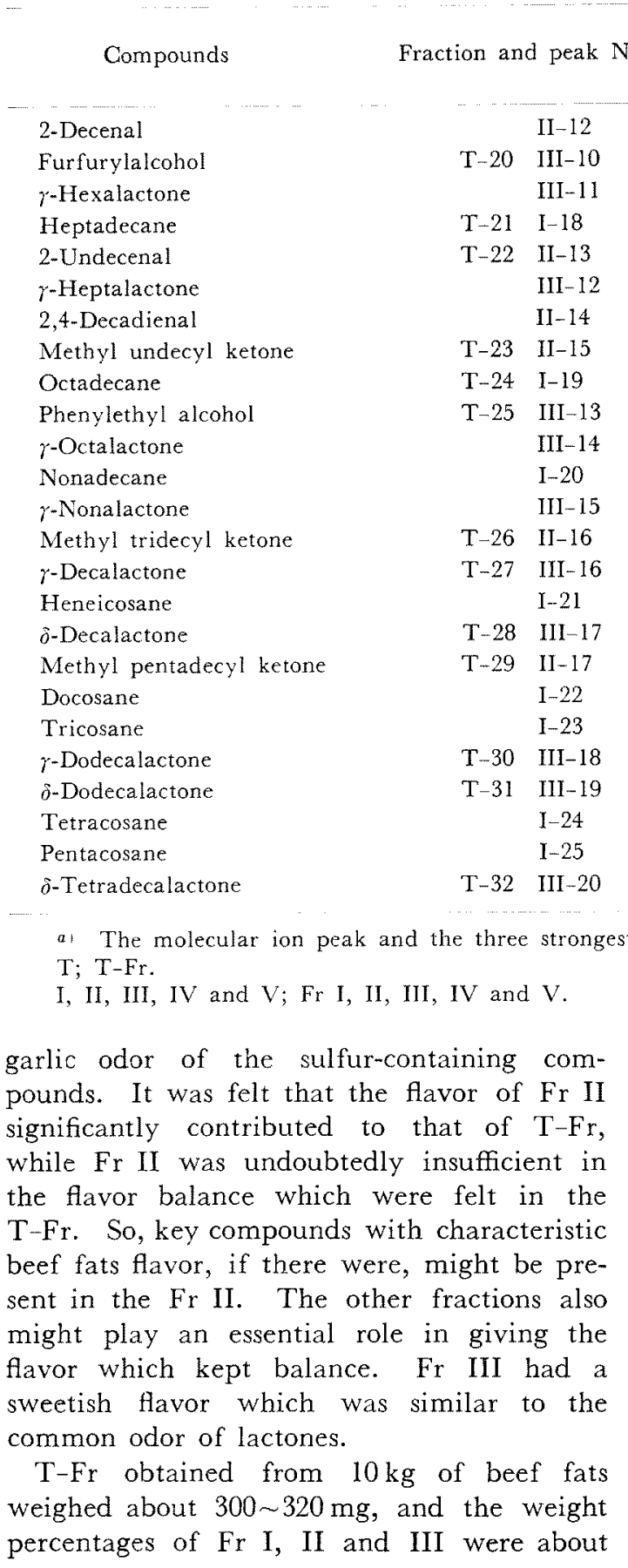

20,75 and 5, respectively, and those of the other fractions were trace. Fr II was the important fraction in the yields as well as in the flavor.

Figure 2 is gas chromatograms depicting separation of $\mathrm{T}-\mathrm{Fr}$ and the separated fractions. Almost all of the components of $\mathrm{T}-\mathrm{Fr}$ were separated into the Fr I, II and III. Fr IV and $\mathrm{V}$ involved the relative small numbers of peaks. The identified compounds, of which peaks have numbers assigned in Fig. 2, are present in Table I. The identification done by both mass spectral data and retention times in gas chromatography might be positive, and what was supported solely by the 


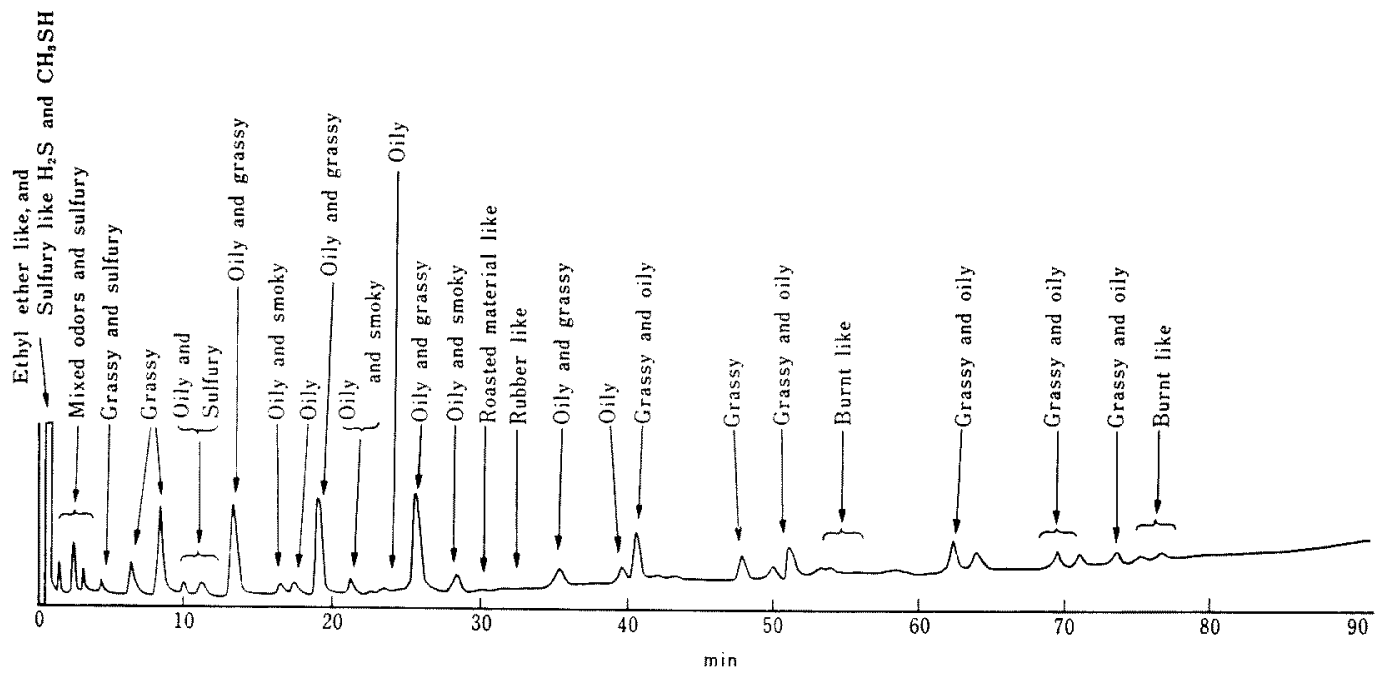

FIG. 3. Gas Chromatogram of Fr II and Descriptions of the Odors Eluted from Column.

mass spectral date might be tentative. Molecular structural assignment of each compound was done by interpretation of the fragmentation patterns of the mass spectra and comparison with the mass spectral data which had been already reported. ${ }^{6 \sim 11}$ The retention times of the flavor components agreed resonably well with those of the corresponding reference compounds.

The components in Fr I consisted of hydrocarbons, in which saturated hydrocarbons were predominant. The long chain hydrocarbons, tridecane to pentacosane, have not been reported yet. It could be considered

6) R. A. Friedel, J. L. Shultz and A. G. Sharkey, Jr., Anal. Chem., 28, 926 (1956).

7) J. A. Gilpin and F. W. McLafferty, ibid., 29, 990 (1957).

8) M.J. O'neal, Jr. and T. P. Wier, Jr., ibid., 23, 830 (1951).

9) A. G. Sharkey, Jr., J. L. Shultz and R. A. Friedel, ibid., 28, 934 (1956).

10) H. A. Bondarovich, A.S. Giammarino, J.A. Renner, F. W. Shephard, A. J. Shingler and M. A. Giznturco, J. Agr. Food. Chem., 15, 36 (1967).

11) H. A. Bondarovich, P. Friedel, V. Krampl, J. A. Renner, F. W. Shephard and M. A. Gianturco, ibid., 15, 1093 (1967). that those saturated hydrocarbons occurred through the decarboxylation and splitting of carbon-carbon chain of higher fatty acids. The various alkylbenzenes were recognized to be produced from beef fats by heating, but almost all of them were not clearly identified.

The identified compounds in Fr II were aldehydes, ketones and esters. And saturated aldehydes, from hexanal to nonanal, were the main constituents in Fr II. A series of the saturated and unsaturated aldehydes have been reported as the flavor of beef fats, ${ }^{1,21}$ and almost all of them might be the thermal oxidation products of free fatty acids and glycerides in beef fats. The methyl ketones with the carbon numbers of $\mathrm{C}_{13}, \mathrm{C}_{15}$ and $\mathrm{C}_{17}$ which might be also thermal oxidation products have not been reported yet.

The flavor of Fr II resembled that of heated beef fats as described above, but among the separated and identifird compounds, there were no compounds which significantly contributed to the odor of heated beef fats. Gas chromatogram of Fr II and the description of odors observed as compounds eluted from the column were shown in Fig. 3. The 


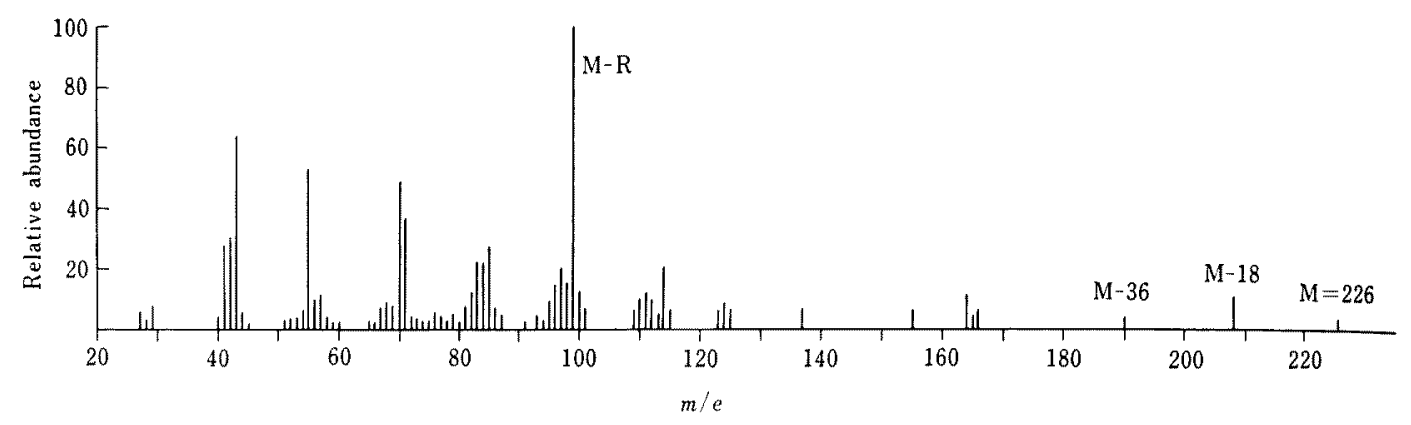

FIG. 4. Mass Spectrum of Peak T-32 (III-20).

coincidence between flavor of the identified compounds and the descriptions of odor was observed, for example, aldehyde was felt to be greenish. There were no sulfur-containing compounds among the identified compounds, although the onion and garlic flavors were observed in the odors eluted from the column. This observation demonstrated that the sulfurcontaining compounds were present in extra small amounts in Fr II, and they influenced on the heated flavor of beef fats, more or less. Therefore, it could be considered that a proper combination of aldehydes, ketones, esters and sulfur-containing compounds contributed to the typical flavor.

Fr III involved the saturated, unsaturated, branched and aromatic alcohols, and a series of lactones. Furfuryl alcohol and phenylethyl alcohol have not previously been reported, but the other alcohols were usual. The identification of a series of lactones and mechanisms of their formation have been reported in the previous paper. ${ }^{12 \sim 141}$ In this report, normal aliphatic $\gamma$ - and $\delta$-lactones $(\gamma$-hexalactone, $\gamma$-heptalactone, $\gamma$-octalactone, $\gamma$-nonalactone, $\gamma$-decalactone, $\delta$-decalactone, $\gamma$ dodecalactone, $\delta$-dodecalactone and $\delta$-tetradecalactone) were identified. The mass spectra

12) K. Watanabe and Y. Sato, Agr. Biol. Chem., 33, 242 (1969).

13) K. Watanabe and Y. Sato, ibid., 32, 1318 (1968).

14) K. Watanabe and Y. Sato, ibid., 34, 464 (1970). of $\gamma$-hexalactone to $\delta$-dodecalactone were shown in the previous paper. ${ }^{14)}$ Mass spectrum of Peak T-32 (III-20) which were identified as normal $\delta$-tetradecalactone is shown in Fig. 4, and this spectrum was agreed with that of standard normal $\delta$-tetradecalactone. The mass spectrum of Fig. 4 had a molecular ion of $m / e 226$ and showed a characteristic peak of $\delta$-lactones at $m / e 99$. The weak peaks at $m / e \mathbf{M}-18$ and $\mathrm{M}-36$ are accepted to indicate the loss of one and two molecules of water from the molecular ion. ${ }^{15,161}$ These eliminations must be a very complicated process, involving several bond ruptures and rearrangements. The identification of this lactones was supported by comparison of the retention time of sample with that of the standard compound.

It has been demonstrated that $\delta$-lactones of chain length longer than ten carbons were produced predominantly from the corresponding hydroxy acids in beef fats, ${ }^{13}$ and $\gamma$ lactones, especially $\gamma$-heptalactone, $\gamma$-octalactone and $\gamma$-nonalactone, were formed from the higher fatty acids which were main components in beef fats. ${ }^{17}$ The lactones detected in this report were characteristic in

15) W. H. McFadden, E. A. Day and M.J. Diamond, Anal. Chem., 37, 89 (1965).

16) E. Honkanen, T. Moiso and P. Karvonen, Acta Chem. Scand., 19, 370 (1965).

17) K. Watanabe and Y. Sato, Agr. Biol. Chem., 35, 278 (1971). 
the $\gamma$ - and $\delta$-lactones described above. So, it might be concluded that the lactones developed from beef fats under the cooking condition were derived from both of their origins, that is, hydroxy acids and fatty acids.

The pyrazine compounds were present in Fr IV and $\mathrm{V}$ The content of nitrogen analysed by Kjeldahl method were in the $0.1 \sim 0.2 \%$ for beef fats used, and the nitrogenous substances might be proteins, peptides, amino acids and phospholipids. These substances probably degrade during cooking to produce ammonia and the other basic compounds. When amino acids and the degraded nitrogenous substances reacted with the available $\alpha$-dicarbonyl in beef fats, pyrazine compounds could occur through amino- carbonyl reaction. ${ }^{5,18}$ Typical odor of pyrazine compounds suggested that they were responsible for the nut-like and peanut-butterlike flavors, and they were found in roasted barley, ${ }^{181}$ coffee, ${ }^{111}$ potato chips, ${ }^{191}$ cocoa, ${ }^{51}$ etc.

As notable constituents other than pyrazine compounds in Fr IV, acetoin was detected. One would expect acetoin to contribute to the flavor of beef fats.

Acknowledgement. The authors wish to express their thanks to Dr. Kazuo Hayashi and his colleagues, Hasegawa Co., Ltd., for their experimental supports.

18) P. S. Wang, H. Kato and M. Fujimaki, Agr. Biol. Chem., 33, 1775 (1969).

19) R. E. Deck and S. S. Chang, Chem. and Ind., 1965,1343 . 